\title{
ANÁLISE COMPARADA DAS ESTRATÉGIAS ORGANIZATIVAS DOS LOBBIES NO PROCESSO CONSTITUINTE DE 1987-881
}

\author{
Lucas Costa \\ Pesquisador de Pós-doutorado em ciência política no Centro de Estudos em Política e Economia \\ do Setor Público da Fundação Getúlio Vargas (Cepesp/FGV). São Paulo, SP, Brasil. \\ E-mail: lucasnfcosta@gmail.com \\ Orcid: 0000-0002-7916-6008 \\ http://dx.doi.org/10.1590/0102-283316/112
}

\section{Introdução}

Passados mais de trinta anos, a constituinte de 198788 ainda instiga a produção de análises diversas, seja pela intrínseca importância histórica, política e jurídica, comum a todos os processos de constitucionalização, mas, sobretudo, pelos elementos que são singulares ao caso brasileiro, entre os quais, a presença de condições em que os atores externos, em especial grupos de interesse, dividiram o protagonismo decisório com os atores internos (parlamentares constituintes e partidos políticos). Ou seja, trata-se, do ponto de vista de interesse científico, de um evento cuja relevância supera seus desdobramentos para a realidade institucional do país, consiste, pois, em um palco privilegiado para a análise do papel dos grupos de interesse e de suas estratégias organizativas sobre processos políticos, quando

1 O autor Lucas Costa agradece à Fundação de Amparo à Pesquisa do Estado de São Paulo (FAPESP) que financiou, através de seu programa de Pós-Doutorado (Processo $n^{\circ}$ 2018/05607-4), a execução parcial da pesquisa apresentada neste artigo. 
"the stakes are high", expressão em inglês para definir jogos de alto risco, nos quais os participantes têm muito a ganhar ou perder. Diversamente, em geral, estudos sobre lobby têm como objeto processos políticos ordinários, onde "the stakes are [comparativamente] low" e os resultados (sejam eles perdas ou ganhos) costumam ser parciais e incrementais. Essa distinção atribuída ao caso brasileiro explica, em parte, o imenso interesse da literatura internacional sobre o processo de constitucionalização nacional (Benomar, 2004; Elkins, Ginsburg e Blount, 2008; Ferrajoli, 2012; Sartori, 1997). A outra parte da explicação advém das particularidades desse produto, isto é, da Constituição de 1988, como a extensão de seu texto - o terceiro maior do mundo (Comparative Constituions Project, 2016), e o número de direitos introduzidos e seu nível de detalhes. Embora o processo e seu produto sejam, obviamente, diferentes partes de uma mesma história, ainda permanecem incompreendidos, 284 como se as particularidades do primeiro se associassem com as do segundo. Um destes enigmas consiste exatamente nos supostos efeitos da participação pública, da atividade lobista em particular, sobre a constitucionalização de um elevado número de direitos sociais.

Neste artigo, analisamos a atuação de grupos de interesse nas áreas da Educação, Saúde e Trabalho, durante o processo constituinte brasileiro de $1987-88$, por meio de uma abordagem que privilegia as estratégias organizativas coletivas desses atores. Trata-se de um modelo de análise que adapta para o contexto de elaboração constitucional a teoria sobre os efeitos benéficos da formação de coalizões lobistas, usualmente aplicada para explicar os movimentos coletivos de lobbies em condições ordinárias, por exemplo, a sua atuação no congresso norte-americano ou no parlamento europeu (Bennedsen e Feldmann, 2002; Hojnacki e Kimball, 1998; Klüver, 2013; Pijnenburg, 1998). Em particular, adotamos e replicamos o modelo de gráficos de 
redes sociais, que consiste em uma técnica analítica bastante empregada em estudos sobre coalizões de grupos de interesse (conforme discutiremos na seção metodológica deste artigo), mas que, novamente, nunca foi utilizada para explicar as estratégias dos lobbies que atuaram no processo constituinte brasileiro. Nosso objetivo, portanto, é mostrar a viabilidade da aplicação desse modelo e de seus pressupostos, devidamente adaptados para o contexto particular de um processo constituinte, para explicar a relação entre estratégias de coalizões (variável independente) e nível de sucesso (variável dependente), este interpretado a partir da capacidade dos grupos de interesse em constitucionalizar suas preferências. Sustentamos que a capacidade de engendrar e manter uma coalizão coesa de interesses foi uma variável determinante para que os lobbies conseguissem influenciar na manutenção ou reforma do status quo, conforme o caso. As conclusões são respaldadas por uma análise de gráficos de redes (nos campos da Educação e Saúde) e por um estudo de caso sobre a atuação de grupos de interesse na área do Trabalho. Em ambos, as variáveis e as inferências teóricas foram constituídas a partir de evidências empíricas primárias.

Em resumo, este artigo dialoga com duas amplas literaturas (constitucionalização de direitos sociais no Brasil e estratégias de atuação lobista) e sua inovação consiste, precisamente, em combiná-las, apresentando contribuições que avançam em ambos os campos. Na próxima seção deste estudo, discutimos os pressupostos teóricos que embasaram nossa investigação sobre o processo constituinte, apontando as características que consideramos imprescindíveis para a compreensão do papel desempenhado pelos grupos de interesse no período. Ainda nesta parte, problematizamos e justificamos a adoção do conceito de lobby em nossa análise. Na terceira seção, descrevemos nossa metodologia, propondo e discutindo um modelo organizativo dos lobbies 
durante a constituinte, bem como indicando as ferramentas utilizadas para testar sua ocorrência (gráficos de redes sociais), esses casos são adaptações da teoria sobre a atuação de coalizões lobistas em contextos legislativos ordinários. Na quarta seção, discutimos preliminarmente as divisões de interesses observadas nas áreas da Educação e da Saúde. Na quinta seção, analisamos o lobby na área do Trabalho, destacando o papel do Departamento Intersindical de Assessoria Parlamentar (Diap) na defesa dos interesses dos trabalhadores na constituinte. Na sexta e última seção, comparamos as particularidades da ocorrência do modelo organizativo proposto por este artigo nas três áreas e como as diferentes estratégias organizativas influenciaram o variável sucesso dos diversos interesses defendidos.

\section{Constituinte 1987-88 e os lobbies}

O processo constituinte de 1987-88 e, em especial, os 286 efeitos da Constituição de 1988 foram extensivamente analisados pela literatura brasileira, mormente pela Ciência Política. Temporalmente, neste artigo, posicionamo-nos explicitamente no período que precedeu a promulgação da Carta, ou seja, estamos interessados em analisar como e por que ela assumiu seu conhecido formato original, no que diz respeito ao seu conteúdo social. Para os propósitos da análise, também declaramos nossa preferência pela abordagem do processo constituinte que considera a combinação dos seus elementos externos e internos. Isto é, a institucionalidade interna da Assembleia Nacional Constituinte (ANC); as suas regras; a organização das bancadas partidárias que a compunha; e as consequentes estratégias de atuação, adaptadas, reformadas e, em alguns casos, impostas pela pressão dos expressivos lobbies.

Consideramos que, em geral, a literatura optou por uma ou outra abordagem, sendo mais proeminente a endógena, com estudos clássicos de Ricardo Coelho e Adriano 
Pilatti (Coelho, 1999; Pilatti, 2008). Sem prejuízo a importantes trabalhos que interpretaram as características exógenas do processo, cuja relevância consiste na descrição do cenário de mobilização popular que caracterizou os anos 1980, embora tenham priorizado o estudo dos movimentos sociais e suas reivindicações, deixando de lado a análise sobre a influência dessa pressão externa na definição de direitos na Constituição (Gonçalves, 2005; Michiles et al., 1989; Pinheiro, 1989; Santos, 2004). Nosso artigo tem a ambição de estabelecer este link, ao menos no que toca as áreas da Educação, Saúde e Trabalho.

A mencionada ambição corresponde a um esforço para compreender a realidade concreta de um processo constituinte, desenrolado em um ambiente de intensa efervescência social. Concordamos com a tese de Eduardo Noronha, segundo a qual, além da evidente transição de uma ditadura para uma democracia, por meio da reforma de instituições democráticas, o processo constituinte também foi pautado pela proposição de uma agenda social, baseada na constatação de que a desigualdade social, acentuada pelo regime militar, era obstáculo para a democratização do país (Noronha, 2010, p. 9-10). A transição brasileira, marcada pela agenda social, importou na abertura de espaço para que organizações externas assumissem um papel relevante na defesa dos interesses que representavam. A convocação da Constituinte, em 1985, acentuou o movimento dos grupos de interesse, que passaram a se organizar visando o processo legislativo futuro (Aragão, 1992, 1994; Mancuso, 2004; Noronha, 2010; Oliveira, 2004).

Esta agenda social também se refletiu nas regras do jogo da ANC, as quais favoreceram a participação popular. Duas importantes agendas no período - social e democrática moldaram uma institucionalidade própria da Constituinte, assinalada por um Regimento Interno profundamente inclusivo do ponto de vista democrático. Destacam-se os 
procedimentos de democracia direta a partir das emendas populares e das audiências públicas nas subcomissões, e, eventualmente, nas comissões da ANC. As duas ferramentas de participação foram amplamente exploradas por grupos de interesse.

Outras duas características institucionais incentivaram a participação pública: (1) o fato de a Constituinte não ter utilizado formalmente nenhum anteprojeto de constituição, em tese, gerou possibilidades ilimitadas de inserção de direitos e, portanto, criou-se a percepção, entre os grupos de interesse, que suas agendas poderiam ser contempladas. (2) A estrutura descentralizada da ANC, organizada a partir de comissões e subcomissões temáticas, permitiu que os lobbies atuassem diretamente em suas áreas de interesse, facilitando a inserção de suas propostas.

Registramos, por fim, que adotamos, novamente, explicitamente e cientes do caráter controverso desta decisão, o 288 conceito de lobby como elemento central de nossa análise. A escolha, porém, está mais relacionada com a intenção de dialogar com a literatura internacional, especialmente a norte-americana, sobre as características nas quais há clara correspondência entre os processos observados lá e aqui, do que com incendiar ainda mais o inesgotável debate sobre a compatibilidade do conceito nos dois ambientes, obviamente tão distintos. Assim, tomamos o conceito de lobby exclusivamente para os fins específicos que se mostraram eficazes para a presente análise: o lobby é um conjunto de atividades relacionadas à prática de levar a um interesse ou um conjunto de interesses aos tomadores de decisão ou aos demais atores que podem influenciar esses tomadores de decisão. Essa prática pode ser resumida na expressão "representação organizada de interesses". O lobby pode ser mais ou menos "profissional", terminologia que utilizamos com frequência neste artigo, de acordo com os métodos utilizados para que a mensagem seja traduzida e 
entregue aos tomadores de decisão. Portanto, há um duplo elemento que incorpora a atividade lobista: tradução de interesses e método de entrega do produto dessa tradução. Denominamos de "tradução", o método pelo qual o interesse é transformado em um conteúdo inteligível para o seu público-alvo. No caso da constituinte brasileira de 1987-88, essas traduções constituíam, sobretudo, projetos constitucionais ou propostas para a área de interesse. ${ }^{2}$ A "entrega" diz respeito aos métodos adotados para que essa tradução chegue aos tomadores de decisão ou aos atores que poderão influenciá-los (pressão "corpo a corpo", divulgação via imprensa, participação em audiências públicas etc.).

\section{O modelo de organização dos grupos de interesse}

Neste artigo, observamos o funcionamento do lobby de longe. Ao invés de analisarmos profundamente as estratégias de "tradução" e "entrega" adotadas por cada um dos grupos de interesse inseridos nas diferentes áreas de interesse consideradas, nossa proposta é entender o funcionamento da macroestratégia dessas entidades, isto é, como se organizam em conjunto para que seus interesses sejam mais bem defendidos na ANC. Sustentamos que esta "macroestratégia" expressou um modelo de organização dos grupos de interesse durante o referido processo constituinte, argumentando que a relação entre esses atores constituiu um padrão de atuação, observado nas áreas consideradas da Educação, Saúde e Trabalho.

O nosso modelo é compatível com o que a literatura internacional sobre lobby vem observando há mais de

\footnotetext{
2 Definimos como área de interesse um espaço no qual seja identificável a intersecção de interesses entre os grupos que o integram. Assim, dentro de uma área temática dos direitos sociais, Educação, por exemplo, podem e existiram, com efeito, mais de uma área de interesse (defensores dos interesses da escola pública e defensores da escola privada). Em termos dos gráficos de redes sociais, ferramentas metodológicas que adotamos neste artigo, as áreas de interesse definem redes distintas, identificáveis.
} 
quarenta anos: grupos de interesse formam "coalizões". Em primeiro lugar, porque as coalizões servem como meios econômicos e eficientes de se formar um bloco mais poderoso (Box-Steffensmeier; Christenson, 2014). Em poucas palavras, elas sinalizam aos tomadores de decisão um amplo apoio sobre determinado assunto, por isso estratégias de coalizão tendem a ser mais eficazes do que estratégias individuais (Esterling, 2004; Mahoney, 2004; Mayhew, 1974). Segundo Box-Steffensmeier (2014), outra vantagem estratégica de se integrar coalizões é que elas servem como canais pelos quais informações e conhecimentos fluem. Nosso modelo também é compatível com estudos mais voltados às teorias sobre redes sociais, isto é, sobre o papel relativo dos grupos de interesse dentro de uma coalizão. Nesse sentido, a centralidade de um grupo é a característica mais importante a ser considerada, pois os grupos mais centrais tendem a ser mais bem informados e parceiros mais atrativos de rede 290 (Box-Steffensmeier; Christenson, 2014). Em geral, a literatura enfatiza a análise sobre como a centralidade afeta o fluxo de informações e, em consequência, as vantagens de se constituir relações com um ou outro grupo (Burt, 2001; Carpenter; Esterling; Lazer, 1998; Granovetter, 1973). Duas particularidades dos processos constituintes em comparação aos processos legislativos ordinários, nos quais esse modelo é tipicamente aplicado, que justificam as adaptações teóricas do modelo que desenvolvemos nesta pesquisa. $\mathrm{O}$ fato de os resultados do processo constituinte consistirem em uma recompensa muito mais elevada do que as premiações em jogo nos processos legislativos ordinários resulta em: (1) uma adaptação das estratégias dos grupos de interesse, que tendem a concentrar todos os seus recursos no processo constituinte, ao invés de, como é comum no processo de legislação ordinária, dilui-los em diversos jogos que se desdobram em um espaço temporal indefinido; e (2) incentiva a criação de grupos de interesse ad hoc, isto é, idealizados, 
formalizados e institucionalizados visando a atuação específica nesse processo constituinte. Ambas as particularidades têm uma mesma implicação: a formação de coalizões privilegia a obtenção de ganhos no curto prazo (i.e., no próprio processo constituinte) em oposição à projeção de estratégias visando ganhos dispersos no tempo. Por essa razão, nosso modelo antefere os elementos de coesão e estabilidade política das coalizões, ou seja, propomos uma análise empírica sobre a formação de coalizões de grupos de interesse no processo constituinte de 1987-88, não para entender o fluxo de informações entre os integrantes da rede, mas para analisar como blocos de interesses, liderados pelo que denominamos "grupo centralizador", influenciaram a dinâmica das relações de pressão externa e o processo decisório.

Propomos um modelo teórico baseado em padrões de atuação dos grupos de interesse nas áreas do Trabalho, Educação e Saúde durante o processo constituinte. O modelo explica o comportamento desses grupos dentro de cada campo de interesse em face das características excepcionais do processo constituinte. Segundo nossa hipótese, para cada área, há dois tipos de atuação lobista: (1) "lobby centralizador": esta categoria é uma adaptação do conceito que a literatura sobre coalizões, analisada por meio de gráficos de redes sociais, denomina de centralidade, geralmente mensurada pelo nível de intermediação (betweenness centrality), um índice que traduz o número de menores caminhos de todos os vértices para quaisquer outros vértices que passam por aquele nó. Traduzindo o vocábulo técnico, a intermediação de centralidade indica o nível de interação de um grupo de interesse com os demais grupos em uma rede de relações. Chamamos este grupo de centralizador para enfatizar, além de sua condição passiva de centralidade (indicada pelo índice de intermediação), os elementos ativos que o caracterizam enquanto o mantenedor da coesão da coalizão, a despeito de incentivos para dissociação. Consideramos que 
há uma tendência de esta condição centralizadora ser exercida por apenas um grupo de interesse (exatamente aquele com o maior nível de intermediação), o qual denominamos "grupo centralizador". Esse grupo exerce estratégias com a finalidade de articular as propostas do conjunto de grupos na área de interesse a qual está inserido. (2) "lobby individual": exercido pelos demais grupos de interesse, os quais denominamos "grupos individuais". Eles seriam, conforme a literatura tradicional, os demais nódulos da rede com menor índice de intermediação. Embora haja interesses em comum entre as demandas defendidas por esses grupos e outros na mesma área de interesse, eles irão atuar de forma individual, por incapacidade de formar um bloco único e coeso, ou por preferirem focar sua atuação em interesses muito específicos, transferindo as demandas consensuais da área de interesse para outro grupo.

A hipótese apresentada implica que, embora houvesse 292 um grande número de grupos de interesse atuando em uma mesma área, a tendência era de que um deles buscasse a centralização das reivindicações e representasse, formalmente ou não, o conjunto dos grupos através de um projeto único para a esfera de interesse. Afirmamos, ainda, que a capacidade deste grupo centralizador em conciliar as diferentes reivindicações entre os grupos e atores na área determinou o seu potencial de influência, ${ }^{3}$ aumentando a chance de o lobby atingir seus objetivos.

Nossas evidências indicam que a tendência de predominância de apenas um "grupo centralizador" sobre os demais "grupos individuais" é explicada pela percepção destes sobre a necessidade de atuação em bloco, dada a capacidade de

\footnotetext{
3 A escolha pelo conceito "potencial de influência", ao invés de simplesmente "influência" se justifica pela constatação de que é próximo do impossível provar influência do lobby. A correspondência entre interesses defendidos pelos grupos de interesse e resultado legislativo, por exemplo, não provam sua influência, pois é impossível afirmar que o resultado se deu em consequência do lobby.
} 
pressão política em um projeto consensual representando os interesses de vários grupos. A análise dos casos mostra que o grupo escolhido como centralizador geralmente é aquele percebido pelos atores políticos dentro de cada área de interesse como detentor de características organizacionais de conciliação (sejam elas condições intrínsecas à própria existência do grupo ou conquistadas por meio de sua habilidade política), além de reconhecida capacidade técnica. Em alguns casos, o "grupo centralizador", em vez de um ator com voz, é a expressão do consenso, o qual é defendido por meio de seus membros (relação esta observada nas áreas da Educação e Saúde).

Uma das diferenças mais substanciais do nosso modelo adaptado de coalizões e o modelo tradicional, que leva em consideração o nível de intermediação e privilegia, do ponto de vista teórico, a centralidade enquanto tradução do fluxo de informações, é a importância que atribuímos à análise sobre os fatores que engendram estabilidade e coesão política às coalizões e suas consequências para o sucesso dos lobbies. A relação entre os "grupos centralizadores" e "individuais" é complexa. O fato de um "grupo centralizador" predominar em uma área de interesse, exercendo um "lobby centralizador", não implica que os "grupos individuais" deixarão de atuar a partir de "lobbies individuais". As duas atuações lobistas coexistem num mesmo momento. Assim, um "grupo individual" pode, ao mesmo tempo em que se associa ao projeto de um "grupo centralizador", atuar através de um "lobby individual". O resultado é uma relação delicada entre os grupos de interesse "centralizador" e "individual". A capacidade política do "grupo centralizador" em conciliar essa relação, negociando com os "grupos individuais", é o que, em grande medida, vai determinar o potencial de influência do "lobby centralizador".

A ocorrência do modelo acima mencionado é demonstrável por meio de gráficos de redes, os quais revelam as 
associações entre os grupos e são a base dos resultados que analisaremos nas próximas seções deste artigo. Gráficos de redes sociais são representações de interações entre atores (chamados, na terminologia própria, de nódulos), as quais constituem alguma forma de relação. Assim, a importância explicativa de um gráfico de redes se define pela natureza das relações estabelecidas, as quais podem ser das mais variadas. Assim, o que importa são os critérios que condicionam a ocorrência de uma associação. Em nosso estudo, elas são estabelecidas quando um grupo legitima ou altera sua posição inicial em função da posição de um outro grupo. Ou seja, a centralidade em nossos gráficos de rede traduz o nível de representatividade que um determinado grupo tem para legitimar uma dada posição sob disputa perante os demais grupos de interesse e, em especial, constituintes. As informações para definir a ocorrência das relações são produto de nossa análise empírica de uma série de fontes 294 primárias, quais sejam, em sua maior parte, as transcrições dos debates constituintes, disponíveis nas atas e anais publicados no site da Biblioteca do Senado Federal, também em documentos produzidos pelos grupos de interesse e publicados nas atas e anais da constituinte, em material de imprensa ou em canais oficiais de comunicação das entidades. Finalmente, foram consideradas entrevistas prestadas por representantes de instituições, estabelecendo formalmente a legitimação de suas posições. A fonte específica utilizada será oportunamente mencionada para cada caso no momento da apresentação dos gráficos.

\section{Educação e saúde: entre o público e o privado}

As temáticas mais proeminentes no debate das áreas da Educação e Saúde foram aquelas que dividiam os interesses públicos e privados. Por essa razão, a divisão também balizou metodologicamente nossa análise, estabelecendo os limites das áreas de interesse e, portanto, definindo os critérios que 
consideramos na construção das redes de relações e as consequentes formações de blocos de interesse. Esses critérios variaram de acordo com as especificidades de cada setor.

Na área da Educação, traduzimos a divisão por meio da questão sobre a transferência de recursos públicos, a qual denominamos como "exclusividade", em referência a um dos três principais posicionamentos (áreas de interesse) gerados: (1) "Exclusividade", posição majoritária entre os grupos de interesse, sustentava que os recursos públicos fossem destinados exclusivamente para as escolas públicas e foi representada pelo principal "grupo centralizador" na área da Educação, o Fórum Nacional em Defesa da Escola Pública na Constituinte (Fórum). (2) "Exclusividade" com ressalvas, defendia que as verbas públicas fossem também investidas em escolas privadas sem finalidade lucrativa e foi apoiada sobretudo pelo lobby confessional, o qual constituiu um segundo "lobby centralizador", representado pela Conferência Nacional dos Bispos do Brasil (CNBB). (3) Transferência sem restrições, concordava que os recursos públicos fossem destinados, indistintamente, para o ensino público e privado com ou sem finalidade lucrativa e foi representada por um único grupo de interesse, a Federação Nacional dos Estabelecimentos de Ensino (FENEN). ${ }^{4}$ Essa divisão metodológica, levando em consideração a "exclusividade" como tema central no debate entre os interesses públicos e privados, bem como as áreas de interesse daí geradas estão em conformidade com as evidências empíricas e, em geral, com a literatura, mas complementando-a. Embora Pinheiro e Maria das Graças Medeiros Tavares, por exemplo, tenham identificado acertadamente a mencionada divisão entre os interesses da educação pública e privada, consideramos que negligenciaram o papel da CNBB (Pinheiro,

\footnotetext{
4 Até o período final da Constituinte, a instituição ainda se chamava FENEN. A partir de 1990, mudou o nome para Confederação Nacional dos Estabelecimentos de Ensino (CONFENEN).
} 
1989; Tavares, 2003). Para Tavares (2003), os interesses da escola privada estavam subdivididos entre dois setores (correspondentes as áreas de interesse 2 e 3, mencionadas acima), o privado leigo, representado pela FENEN, e o privado confessional, representado pela Associação Brasileira de Escolas Superiores Católicas (ABESC) e a Associação de Educação Católica do Brasil (AEC). Esses dois e outros, também ignorados pela literatura, como a Associação Educativa Evangélica (AEE) e o Conselho dos Reitores Universitários do Brasil (CRUB) (embora este não fizesse parte do setor confessional) defenderam a mesma posição e foram, conforme nosso modelo, "grupos individuais" que desempenharam um papel secundário, comparados à CNBB.

Na área da Saúde, o conflito entre os interesses públicos e privados foi expresso por meio das diferentes propostas em torno da criação do Sistema Único de Saúde (SUS), cada qual defendida com intensidades variadas pelos grupos 296 representantes de duas correntes principais: (1) Movimento Sanitarista, representado pelas entidades que buscavam a reforma sanitária através de uma proposta de universalização e fortalecimento do setor público de saúde; e (2) Setor Privado, cujo objetivo principal era privilegiar a iniciativa privada na área da saúde e foi representado por entidades vinculadas às formas corporativas de comercialização dos serviços de saúde. Também identificamos, em conformidade com a literatura, uma terceira corrente, embora ela fosse alheia ao debate sobre o papel do setor privado no sistema público de saúde. Trata-se do chamado Grupo Institucional, representado pelo Ministério da Saúde e, sobretudo, pelo Ministério da Previdência Social, o qual buscava manter seu papel central de administrador da saúde brasileira por meio do Instituto Nacional de Assistência Médica da Previdência Social (Inamps).

Do ponto de vista metodológico, a divisão entre as três correntes não pôde ser traduzida sob uma única e indistinta 
questão, como a "exclusividade", no caso da Educação. Por isso, propomos uma abordagem complementar, sustentando que essas três áreas de interesses se organizaram em torno de três grandes debates na esfera da Saúde: (1) a questão da saúde como direito do cidadão e dever do Estado, rompendo com o modelo de medicina previdenciária e voltando o sistema nacional de saúde para o princípio da universalidade; (2) questão do arcabouço institucional, isto é, como seria organizado administrativamente o sistema nacional de saúde; e (3) questão do financiamento. Esses três grandes temas constituíram o "tripé do debate sobre saúde", nas palavras de José da Rocha Carvalheiro, representante da Sociedade Brasileira para o Progresso da Ciência (SBPC), em audiência pública na constituinte (Brasil, 1987c, p. 182). Consideramos que o referido tripé dividiu os grupos de interesse em duas grandes áreas, a primeira identificada com propostas associadas à estatização do sistema nacional de saúde e a segunda com propostas defendidas pelo setor privado. Trata-se de um tema amplo que envolveu diversos subtemas, mas que tem como sua coluna vertebral o que criamos e denominamos de "espectro da estatização", uma expressão gráfica sobre os variados posicionamentos em torno do tamanho do papel do Estado no sistema de saúde nacional, conforme representado na Figura $1 .^{5}$

\footnotetext{
5 As entidades são, da esquerda para a direita (em azul, no gráfico, os grupos que pertenciam à CNRS): Central Única dos Trabalhadores (CUT), Coordenação Nacional de Secretárias de Saúde (CONESPE), Associação Brasileira de Enfermagem (ABEn), Coordenação Nacional de Associações de Moradores (CONAM), Sindicatão, Federação Nacional dos Médicos (FENAM), Conselho Federal de Medicina (CFM), Conselho Nacional de Secretarias Municipais de Saúde (CONASEMS), Associação Brasileira de Pós-Graduação em Saúde Coletiva (ABRASCO), Associação Paulista de Saúde Pública (APSP), Confederação das Santas Casas de Misericórdia do Brasil (CMB), Conselho Federal de Farmácia (CFF), Instituto Nacional de Assistência Médica da Previdência Social (Inamps), Conselho Nacional de Secretarias de Saúde (CONASS), Fundação Oswaldo Cruz (Fiocruz), Centro Brasileiro de Estudos de Saúde (CEBES), Comissão Nacional da Reforma Sanitária (CNRS), Ministério da Saúde (MS), Unimed, Sociedade Brasileira de Nefrologia (SBN), Associação Brasileira de Hospitais (ABH),
} 
Figura 1

Espectro da estatização

\begin{tabular}{|c|c|c|c|c|c|}
\hline Estatização Total & & $\begin{array}{c}\text { Associação do } \\
\text { Setor Público } \\
\text { com } \\
\text { Filantrópicas }\end{array}$ & & & $\begin{array}{l}\text { Associação do } \\
\text { Setor Público } \\
\text { om Lucrativas }\end{array}$ \\
\hline $\begin{array}{l}\text { CUT CONAM } \\
\text { CONESPE }_{\text {ABEn }}\end{array}$ & $\begin{array}{c}\text { FENAM } \\
\text { Sindicatão }\end{array}$ & $\begin{array}{l}\text { CFF } \\
\text { ABRASCO } \\
\text { APSP } \\
\text { CMB }\end{array}$ & $\begin{array}{c}\text { CNR } \\
\text { MS } \\
\text { Inamps } \\
\text { Fiocruz } \\
\text { CEBES } \\
\text { CONASS }\end{array}$ & $\begin{array}{r}\text { SBN } \\
\text { Unimed }\end{array}$ & $\begin{array}{c}\text { ABH } \\
\text { FBH } \\
\text { ABRAMGE } \\
\text { FENAESS } \\
\text { IPCC }\end{array}$ \\
\hline
\end{tabular}

Fonte: Elaboração própria.

Na extrema esquerda, posicionamos o ponto correspondente à posição que chamamos de "Estatização Total". Seus defensores propunham que o sistema nacional de saúde fosse totalmente administrado pelo Estado, sendo abolido qualquer convênio com hospitais da rede privada, podendo 298 ser admitida a liberdade de atuação do setor privado, desde que independente dos recursos públicos. Essa posição apresentava um problema de caráter prático, admitido até mesmo pelos seus defensores. O modelo de saúde brasileiro então vigente privilegiava a constituição de convênios com o setor privado, sendo ainda muito incipiente a rede estatal de hospitais. Assim, seria inevitável que o processo de estatização se desenvolvesse gradualmente, mantendo-se em algum grau uma associação com o setor privado enquanto se promovia o aumento da rede de hospitais do Estado.

Ao problema prático do processo de estatização, apresentavam-se alternativas, temporárias ou definitivas, traduzidas na possibilidade de relação entre o setor público e o privado. No centro do espectro, posicionamos o ponto

Federação Brasileira de Hospitais (FBH), Associação Brasileira de Medicina de Grupo (ABRAMGE), Federação Nacional dos Estabelecimentos de Serviços de Saúde (FENAESS) e Instituto de Estudos dos Problemas Contemporâneos da Comunidade (IPCC). 
correspondente à posição que chamamos de "Associação do Setor Público com Filantrópicas”. Os defensores dessa posição propunham que o setor público se associasse ao setor privado, mas apenas com os hospitais filantrópicos, sem finalidade lucrativa. Em uma posição intermediária entre o ponto à esquerda e o centro do espectro, classificamos as entidades que defendiam essa associação apenas em caráter temporário, enquanto reforçava-se a rede estatal de hospitais.

Na extrema direita, alocamos o ponto correspondente à posição "Associação do Setor Público com o Setor Privado Lucrativo". Seus defensores propunham que o Estado, ao invés de investir na construção de uma rede própria de assistência médica, garantisse o direito à saúde por meio de convênios com o setor privado, inclusive com o privado lucrativo, isto é, advogavam pela manutenção do status quo. Ocupando posições intermediárias entre o centro e o ponto à direita do espectro, classificamos as entidades que propunham que tais associações fossem estabelecidas em caráter transitório, defendendo um fortalecimento da rede pública de assistência à saúde.

\section{Trabalho: a centralidade do lobby do Diap}

Embora não disponhamos, para o caso da atuação de grupos de interesse na área Trabalho, de uma análise de gráfico de redes, consideramos que os conceitos desenvolvidos nas seções anteriores são aplicáveis a partir de nossas conclusões, estabelecidas em um estudo de caso que desenvolvemos sobre o papel do Diap no período (Costa, 2016). Desde sua criação, em 1983, o Diap se concentrou na articulação dos interesses dos trabalhadores, sendo o principal responsável pela superação da divisão política entre as principais entidades sindicais da época. A organização coordenou um improvável pacto, unindo em um projeto os interesses consensuais das entidades sindicais 
de trabalhadores, incluindo rivais históricos, como a CUT e a Central Geral dos Trabalhadores (CGT). Ela também superou as expectativas que sugeriam a elaboração de uma Constituição mais conservadora. Essa afirmação não negligencia a influência da variável institucional na "virada de jogo". Consideramos, por exemplo, imprescindível a estrutura de funcionamento da ANC no que concerne ao fato da Comissão de Sistematização não ter elaborado um anteprojeto inicial antes do começo dos trabalhos das comissões temáticas. Fato que privilegiou a capacidade decisória das subcomissões e comissões temáticas, onde os constituintes podiam ser, e foram, mais favoráveis ao projeto do Diap. Toda a atuação da organização durante as duas primeiras fases, quando propôs, orientou e pressionou, conseguindo aprovar seu projeto, e foi fundamental para que não se perdesse tudo nas fases finais da constituinte, quando a maioria passou a ser conservadora, portanto, em geral, resistente às 300 suas propostas.

Sustentamos que o sucesso da organização corresponde ao seu desenho institucional, uma adaptação do lobby altamente profissionalizado dos sindicatos de trabalhadores norte-americanos, em especial a American Federation of Labor and Congress of Industrial Organizations (AFL-CIO), às oportunidades de participação fornecidas pelo processo constituinte. O Diap se destacou desde sua criação pela capacidade técnica, a qual pode ser exemplificada pelos diversos estudos e propostas coordenadas pela instituição e elaborados em parceria com o corpo jurídico das entidades sindicais filiadas. Esses estudos e propostas eram elaborados com alto rigor técnico, o que lhes dava legitimidade. Além disso, o Diap mostrou-se eficiente na divulgação de seus interesses, através de publicações periódicas, como o "Boletim do Diap" e o "Jornal do Diap", os quais eram distribuídos para as entidades sindicais de trabalhadores, membros do Congresso (deputados e senadores), órgãos 
governamentais e jornalistas da grande imprensa. Assim, o material produzido pelo Diap era multiplicado a partir da reprodução por diversos grandes jornais e pela imprensa sindical (Costa, 2016).

A capacidade de articulação política do Diap também está associada à sua opção de atuar apenas em defesa de interesses consensuais da classe trabalhadora e da capacidade política de Ulisses Riedel de Resende, seu criador e diretor-técnico. O prestígio de Riedel foi fundamental para viabilizar o projeto do Diap. Influente advogado trabalhista, Riedel era bem relacionado com as principais lideranças sindicais do país, que nele confiavam (Costa, 2016).

O Diap conseguiu importantes vitórias na Constituinte. A organização acompanhou de perto todas as matérias de interesses para a classe trabalhadora. Na Subcomissão dos Direitos dos Trabalhadores e Servidores Públicos, o DIAP apresentou seu projeto em audiências públicas e coordenou os constituintes para que aprovassem suas propostas. $\mathrm{O}$ relatório final da Subcomissão aprovou integralmente o projeto da organização. Verificamos, também, uma ampla vitória na Comissão da Ordem Social, na qual, inclusive, foram aprovadas propostas polêmicas do projeto, como a estabilidade no emprego e a jornada de trabalho de quarenta horas semanais (Costa, 2016).

Embora, em alguns momentos, o consenso das entidades sindicais tenha enfrentado atritos, ele permaneceu sólido durante quase toda a Constituinte. No momento em que mais sofreu pressões, reflexo, sobretudo, da rivalidade entre a CUT e a CGT, a ANC já estava próxima de seu fim. A atuação do Diap encontrou mais resistência quanto maior era o número de constituintes necessários para aprovar suas propostas (Costa, 2016).

Consideramos o saldo final amplamente favorável aos interesses dos trabalhadores, sobretudo se considerarmos as expectativas negativas nos anos que antecederam à 
Constituinte. As duas maiores derrotas do Diap foram a não aprovação da estabilidade no emprego e da jornada de quarenta horas, a qual foi alterada para 44 horas no texto do anteprojeto da Comissão de Sistematização. Apesar desses reveses pontuais, a Constituição de 1988 ficou marcada na história pelo amplo espaço concedido aos direitos sociais e do trabalho (Costa, 2016).

Em resumo, utilizando a terminologia adotada neste artigo, consideramos o Diap um modelo de "grupo centralizador", enquanto outros signatários de seu projeto constitucional, incluindo CUT e CGT seriam grupos individuais. Além de articular um projeto consensual para os grupos de interesses que defendiam os direitos dos trabalhadores, o Diap atuou diretamente pressionando os constituintes a adotarem suas propostas. Essa segunda característica diverge dos padrões de "lobbies centralizadores" formados nas áreas da Educação e Saúde, conforme analisaremos a seguir.

\section{Análise comparativa das estratégias organizativas dos grupos de interesse nas áreas do trabalho, educação e saúde}

Em comparação à área do Trabalho, as áreas da Educação e Saúde são distintas em um aspecto fundamental: as propostas dos principais "grupos centralizadores" formados nesses campos foram defendidas pelos "grupos individuais" que os compunham, e não pelas próprias entidades centralizadoras. A formação do "lobby centralizador" na Educação e Saúde seguiram trajetórias históricas muito semelhantes. Ambas emergiram de movimentos reivindicatórios pela valorização do setor público, traduzidas em grandes fóruns de debates, a IV Conferência Brasileira de Educação (IV CBE) na área da Educação, e a VIII Conferência Nacional de Saúde (VIII CNS) na área da Saúde, as duas realizadas em 1986, respectivamente em Goiânia e Brasília. Elas recomendaram a formação de uma 
entidade responsável por traduzir suas reivindicações em uma proposta constitucional e defendê-la na Constituinte. Na Educação, foi criado o Fórum, em fevereiro de 1987; e na Saúde, a CNRS, em agosto de 1986. O Fórum seguiu as orientações da IV CBE e representou o lobby do ensino público na Constituinte. A CNRS se afastou das recomendações mais estatizantes da VIII CNS e elaborou uma proposta constitucional mais moderada, que acomodou também os interesses do setor privado. Essa diferença teve implicações distintas na organização dos lobbies em cada uma das áreas, conforme expresso nos gráficos de rede 1 e 2 .

\section{Gráfico de rede 1}

"Exclusividade" na educação

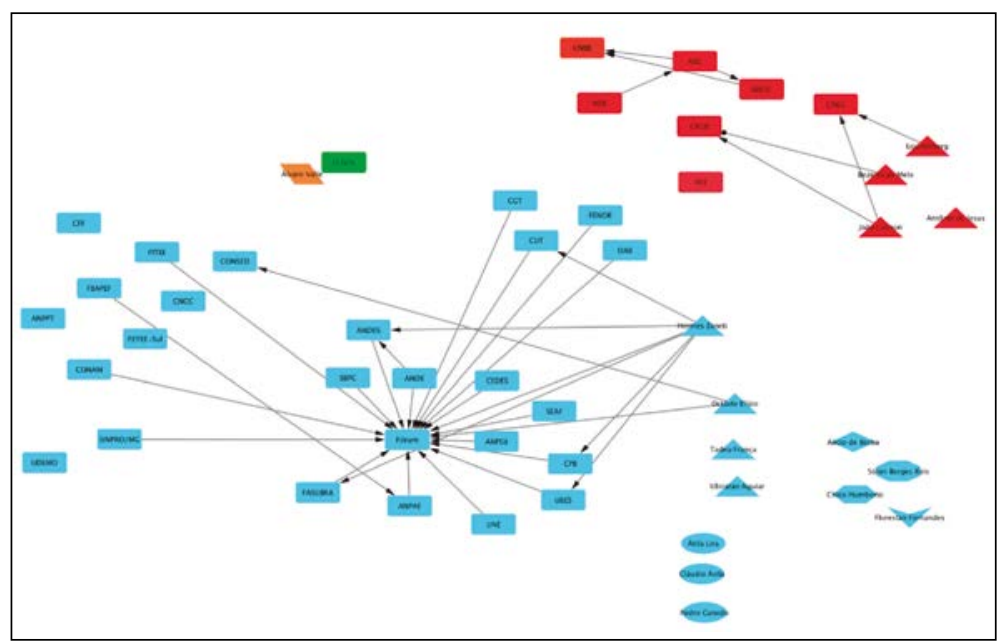

Fonte: elaboração própria com auxílio do software Cytoscape (versão 3.4).

O gráfico de rede 1 mostra a relação entre os grupos de interesse, enquanto que o gráfico de rede 2, entre eles e os constituintes nas áreas da Educação e Saúde. ${ }^{6}$ As

\footnotetext{
6 Foram considerados apenas os constituintes cujas posições foram identificáveis, seja por meio de suas falas durante a referida Subcomissão, ou por meio de entrevistas e depoimentos registrados pela imprensa. Outrossim, as relações entre
} 
fontes para a definição de cada associação estão descritas no anexo 1 deste artigo. Elas foram identificadas com base em seus posicionamentos nas questões analisadas (e já discutidas neste estudo). O gráfico 1 representa atores, posições e relações: (1) três posições quanto à questão da "exclusividade", (1.1) azul, os atores favoráveis, (1.2) vermelho, os atores favoráveis com restrições (recursos exclusivos para o ensino público, salvo as escolas privadas sem finalidade lucrativa) e (1.3) laranja, os atores desfavoráveis (recursos transferidos indistintamente para ensino público e privado); (2) dois tipos de atores, (2.1) retângulos, as entidades, (2.2) constituintes, as quais podem ser de sete partidos políticos diferentes, (2.2.1) triângulos, do Partido do Movimento Democrático Brasileiro - $\mathrm{PMDB}^{7}$, (2.2.2) elipses, do Partido da Frente Liberal - PFL $^{8}$, (2.2.3) diamantes, do Partido Democrático Social - PDS, (2.2.4) hexágonos, do Partido Democrático Trabalhista - PDT, (2.2.5) octógonos, 304 do Partido Trabalhista Brasileiro - PTB, (2.2.6) formatos de "V", do Partido dos Trabalhadores - PT e (2.2.7) paralelogramos, do Partido Liberal - PL; (3) dois tipos de relação, (3.1) quando um ator (constituinte ou entidade) legitimou sua posição por meio da posição de um segundo ator e (3.2) quando um ator alterou sua posição inicial por uma segunda de um outro ator. ${ }^{9}$

O gráfico 2 representa os mesmos elementos do gráfico 1, mas para a área da Saúde. Difere-se do primeiro apenas quanto às posições e à inclusão de um novo ator. As

constituintes e grupos de interesse, ou entre um grupo e outro, foram atribuídas com base em declarações desses atores (no caso dos grupos de interesse, as falas de seus representantes) durante à Subcomissão ou registros da imprensa.

7 Em 2017, O PMDB escolheu adotar a sigla MDB - Movimento Democrático Brasileiro, que é a nomenclatura original do partido quando fundado em 1966.

8 O PFL, partido político criado em 1985, mudou de nome em 2007 e passou a ser chamado de Democratas (DEM).

9 Nos dois casos, a seta parte do ator que legitimou sua posição para o ator cuja posição foi fonte de sua legitimação. 
posições são de três tipos: (1) vermelha, setor privado não deve participar do SUS, ou participar apenas em caráter transitório; (2) verde, admitida a participação do setor privado em caráter permanente, mas com ao menos uma restrição à sua participação (associação apenas com as filantrópicas; preferência às filantrópicas; filantrópicas e lucrativas, mas com contrato de direito público); (3) azul, setor privado deve participar do SUS sem nenhuma restrição. Foi incluído o ator "CNS", em referência às recomendações da VIII CNS. Não se trata de uma entidade, mas a Conferência elaborou um relatório com orientações, as quais serviram como base de legitimação das posições de grupos de interesse.

\section{Gráfico de rede 2}

Estatização da saúde

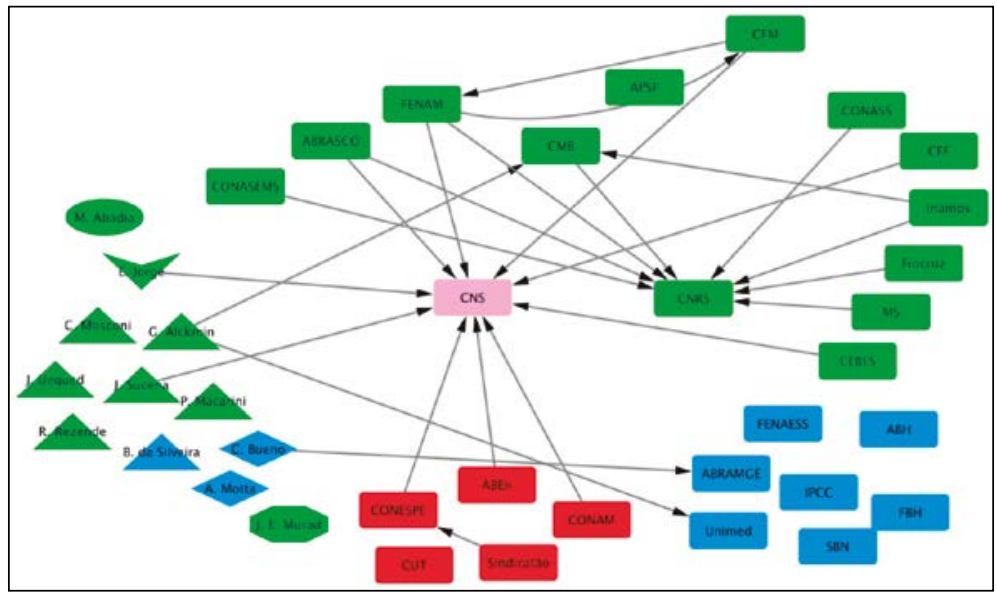

Fonte: elaboração própria com auxílio do software Cytoscape (versão 3.4).

Na Educação, constituiu-se uma clara centralização dos interesses do setor público em torno do Fórum. A representatividade do grupo foi expressa quantitativamente pelo número de entidades-membro que participaram das audiências públicas na Subcomissão da Educação, Cultura e Esportes e qualitativamente pelo potencial de 
influência dessas entidades, cujas propostas foram incorporadas ao discurso majoritário dos constituintes membros da Subcomissão, bem como aos resultados normativos traduzidos no anteprojeto elaborado. Pelo fato de o Fórum ser a expressão clara de um único setor, na área da Educação, formou-se um outro "grupo centralizador" exercendo os interesses do setor privado confessional, representado pela CNBB, que encarnou um dos mais influentes lobbies da Constituinte, atuando não apenas na Educação.

Apesar de muito mais modesto do ponto de vista quantitativo (apenas duas outras entidades subscreveram a proposta da CNBB), seu lobby exerceu influência decisiva, mostrando que os resultados constitucionais foram o produto de uma complexa relação de variáveis, as quais incluíam além da representatividade da rede de relações entre grupos de interesse, a capacidade técnica do "grupo centralizador" ou de seus "grupos individuais", a composição ideológica dos 306 fóruns sobre os quais esses lobbies seriam exercidos (diferentes fases da ANC) e as possibilidades determinantes das regras do jogo, sejam elas as normas do Regimento Interno da Assembleia Nacional Constituinte (RIANC), ou a habilidade política de grupos partidários de as moldarem ao sabor de seus interesses.

No caso da área do Trabalho, conforme argumentamos, o Diap contava ao mesmo tempo com significativa representatividade e capacidade técnica para exercer um lobby profissional. O maior obstáculo foi a composição ideológica da ANC, majoritariamente conservadora, portanto, avessa às suas propostas mais progressistas. Porém, orientado pelo projeto do Diap, o grupo progressista do PMDB, apoiado pelos partidos de esquerda, conseguiu reverter as expectativas mais pessimistas, e instalaram-se inegáveis e surpreendentes avanços na área dos direitos do trabalho.

Na área da Educação, o Fórum contou com semelhante representatividade, porém o exercício direto das ações 
lobistas foi diluído entre seus membros, sem o impacto do influente e temido lobby do Diap. Enquanto a composição da Subcomissão inicial favoreceu a aprovação de suas propostas, elas foram retrocedidas pela reação conservadora nas demais fases, em que a maioria era amplamente conservadora, em especial na fase final de Plenário, quando formou-se o bloco conservador denominado Centrão, que representava os interesses da escola privada. A estratégia do "lobby centralizador" exercido pelo Fórum foi eficiente atingindo seu ponto ótimo durante a Subcomissão. Nas demais fases, as propostas do segundo "grupo centralizador" da área da Educação, a CNBB, passou a prevalecer. A posição da CNBB beneficiou-se por ser moderada entre os radicalismos das propostas centralizadas pelo Fórum de um lado, e do setor privado lucrativo, representado pela FENEN, do outro.

Na área da Saúde, formou-se um grupo centralizador formalmente expresso pela CNRS; porém, como esta não foi uma evolução natural das ambições da Conferência (VIII CNS) que lhe precedeu, constituindo-se um continuum dissociativo de propostas que se afastavam dos princípios estatizantes, na prática, formaram-se dois "grupos centralizadores": CNRS e CNS.

A CNS representou os interesses mais estatizante na área da Saúde, identificados com os sanitaristas. A CNRS representou propostas mais moderadas, constituindo-se a base do lobby pragmático dos sanitaristas, o qual contou com aderência variável entre seus próprios membros. Em comparação com o "lobby centralizador" do Diap, na área do trabalho, e do Fórum, na área da educação, o lobby da CNRS distingue-se especialmente pela sua vulnerável capacidade agregadora. A dinâmica desagregadora entre "lobby centralizador" e "lobby individual" foi observada com muito mais intensidade na esfera da Saúde do que nas demais. A despeito disso, se compararmos o projeto constitucional da CNRS com o texto final da Constituição de 1988, 
encontraremos uma correspondência muito maior entre os dispositivos do que aquela observada entre a mesma Carta de 1988 e as propostas do Diap e do Fórum. Ou seja, do ponto de vista normativo, o lobby da CNRS foi mais eficiente do que os demais, embora tenha sido o menos sólido em termos de coesão de seus membros.

O que isso significa para nosso modelo de organização lobista? No limite, os resultados verificados em relação à correspondência normativa dos projetos dos "lobbies centralizadores" com o texto final da constituição indicam um contrassenso quando constatada uma correspondência mais positiva justamente no mais frágil dos "lobbies centralizadores". Mas os resultados não enfraquecem necessariamente nossa hipótese. Sustentamos que há uma tendência de formação de "lobbies centralizadores" em cada uma das áreas de interesse, e que o potencial de influência desses lobbies seria maior quanto melhor sua capacidade de centralizar 308 interesses. O uso do termo "potencial" não é fruto de mera semântica, ele exprime implicitamente que há outros fatores determinantes na capacidade de um lobby influenciar nas decisões. No caso da área da saúde, embora o "lobby centralizador" da CNRS seja o mais frágil entre as três áreas analisadas no que diz respeito a sua capacidade agregadora, é ao mesmo tempo o mais bem constituído do ponto de vista pragmático-normativo. É o que melhor exprimiu o consenso dentro da macroárea da Saúde, pois acomodou as propostas de campos de interesses opostos (setor público e setor privado).

Os resultados da análise das redes permitem complementar nossa proposta teórica sobre os padrões de organização dos grupos de interesse no processo constituinte de 1987-88. Embora em termos gerais seja verdadeiro de que a capacidade agregadora de um "lobby centralizador" é um fator determinante de seu sucesso, essa relação é mais sensível quando (1) o "grupo centralizador" atua dentro de uma 
área de interesse específica, isto é, em oposição aos interesses defendidos por uma outra área; e (2) o "lobby centralizador" incide sobre a intersecção de duas áreas de interesse, a tendência então é que a desagregação seja menos relevante.

Analisemos os dois cenários com exemplos das relações expressas nas redes. O primeiro cenário é compatível com a estrutura do "lobby centralizador" das áreas do trabalho e da educação. Diap e Fórum defenderam, respectivamente, os direitos dos trabalhadores em oposição aos interesses dos empresários e os interesses da educação pública em oposição aos interesses da educação privada. Se o Diap ou o Fórum enfrentassem um processo intenso de dissociação de seus "lobbies centralizadores", o que estaria ruindo seria sua própria área de interesse, em oposição a uma área de interesse concorrente.

Se as entidades sindicais resolvessem negar o projeto agregador do Diap, estariam preterindo as posições do "lobby centralizador" por outra posição semelhante a ela, mas igualmente oposta aos interesses dos empresários. Aliás, as evidências sugerem que foi exatamente isso que aconteceu em relação à Federação das Indústrias do Estado de São Paulo (Fiesp), identificada pela literatura como "lobby centralizador" da área de interesse dos empresários (embora os autores não tenham usado essa mesma terminologia) (Costa e Troiano, 2016) por meio do mapeamento dos atores envolvidos, sejam eles parlamentares ou não. Como recorte analítico, parte-se da ideia geral de que a Federação das Indústrias do Estado de São Paulo (FIESP. A Fiesp foi incapaz de manter a coesão entre os grupos individuais que centralizava, e, como consequência, seu lobby ruiu drasticamente no processo constituinte, que testemunhou a defesa dos interesses empresariais por meio de "lobbies individuais", com baixa expressão, comparado ao poder econômico que representavam. O fracasso dos empresários beneficiou a área de interesse oposta, exatamente aquela 
representada pelo "lobby centralizador" do Diap. Da mesma forma, o fracasso do Fórum em agregar os interesses da educação pública beneficiaria diretamente o ensino privado.

O segundo cenário apresenta características diferentes. Ele é compatível com a CNRS, que defendeu propostas de duas áreas de interesse opostas, ou propostas que atendessem pela metade os interesses dos setores de saúde público e privado. Um intenso processo de dissociação nesse contexto não beneficia diretamente nenhuma das áreas de interesse. Por isso, embora a representação gráfica das redes na área da Saúde revele a defesa de posições distintas entre os "grupos individuais" associados ao "grupo centralizador", não decorreu deste processo dissociativo o fracasso do "lobby centralizador", mas o oposto - comparadas as três áreas analisadas -, foi a CNRS que logrou a maior correspondência normativa entre seu projeto e o resultado final (a Constituição). Os "grupos individuais" dissidentes que o compunham preteri310 ram suas propostas por outras à esquerda e à direita em um processo de prejudicialidade mútua das áreas de interesse, cujo produto foi, portanto, neutro. Neutralizados os opostos, subsistiu a posição central e moderada, representada exatamente pelo "lobby centralizador" da CNRS.

\section{Considerações finais}

Neste artigo, mostramos quais foram as estratégias organizativas dos grupos de interesse das áreas da Educação, Saúde e Trabalho, durante o processo constituinte de 1987-88, e como elas afetaram o sucesso de seus lobbies. O modelo analítico adotado consistiu em uma adaptação da teoria sobre a formação de coalizões de grupos de interesse e, mais especificamente, do uso da técnica de gráficos de redes sociais para demonstrar a centralidade dos grupos nas redes constituídas. Nosso modelo se difere da teoria tradicional de coalizões por ser aplicado sobre um contexto de constitucionalização, enquanto a metodologia 
é majoritariamente empregada em contextos de processos legislativos ordinários. Adaptamos o modelo para privilegiar os elementos de construção e manutenção da coesão política das coalizões em oposição à ênfase ao fluxo de informações, que tradicionalmente descreve os estudos sobre coalizões em cenários de legislação ordinárias. Esta adaptação justifica-se pelo fato de que na constituinte os recursos dos lobbies se concentram em um único processo, pois os potenciais ganhos superam as estratégias caracterizadas pela distribuição dos recursos ao longo de processos futuros. Evidências de criação de grupos de interesse visando especificamente a constituinte reforçam essa alegação.

A análise qualitativa da atuação desses lobbies ao longo do processo constituinte, combinada com os elementos gráficos mencionados, refinou a hipótese teórica sintetizada pelo modelo organizativo proposto. Mostramos que, de fato, a capacidade agregadora dos grupos que centralizaram os lobbies em cada área de interesse foi variável determinante para imprimir força política às suas demandas e, consequentemente, aumentar a chance de seu sucesso (constitucionalização de suas propostas, ou evitar que propostas opostas aos seus interesses fossem constitucionalizadas). Porém, o caso da área da Saúde revelou especificidades quanto à ocorrência do modelo: o desenho da distribuição dos blocos de interesse determina a força da variável capacidade agregadora, a qual é mais sensível quanto maior for a distância entre os interesses defendidos pelos principais lobbies centralizadores. Ou dizendo a mesma coisa, mas partindo do lado inverso da afirmação lógica, quanto mais ao centro (quanto mais interesses acomodar dos lados opostos) estiver um lobby centralizador, menos relevante é um movimento dissociativo e, consequentemente, menos impactante é a influência da variável capacidade agregadora. Nesse caso, o movimento dissociativo beneficia igualmente as áreas de interesses opostas e, portanto, o resultado é neutro. 
Embora o artigo consista em uma análise focalizada (três áreas dos direitos sociais ao longo do processo constituinte), as evidências sugerem, embora ainda não as tenhamos para comprovar, que o padrão observado pode ter se repetido em outras áreas da $\mathrm{ANC}$, bem como em processos constituintes realizados em outros países e repetir-se-á em processos futuros. De forma concreta, o estudo busca contribuir com o avanço de duas agendas de pesquisa distintas, mas potencialmente associadas, quais sejam, a teoria sobre coalizões de grupos de interesse e as interpretações sobre a relação entre características de processos constituintes e seus efeitos sobre o produto final - a Constituição.

\section{Lucas Costa}

Doutor em Ciência Política pela Universidade Federal de São Carlos (UFSCar). Pesquisador de Pós-doutorado na Escola de Administração de Empresas de São Paulo da 312 Fundação Getúlio Vargas (FGV/EAESP). É pesquisador-membro do Centro de Estudos em Política e Economia do Setor Público (CEPESP). Pesquisa Constitucionalismo Comparado e Lobby.

\section{Bibliografia}

ARAGÃO, Murillo de. 1992. Os grupos de pressão no congresso nacional: abordagem ao papel dos grupos no legislativo, seus procedimentos e legislação pertinente. Brasília, DF: Universidade de Brasília.

ARAGÃO, Murillo de. 1994. Grupos de pressão no congresso nacional: como a sociedade pode defender licitamente seus direitos no poder legislativo.

São Paulo: Maltese.

BENNEDSEN, Morten; FELDMANN, Sven E. 2002. Lobbying legislatures. Journal of Political Economy, v. 110, n. 4, pp. 919-946.

BENOMAR, Jamal. 2004. Constitution-making after conflict : lessons for Iraq. Journal of Democracy, v. 15, n. 2, pp. 81-95.

BOX-STEFFENSMEIER, Janet M.; CHRISTENSON, Dino P. 2014. The evolution and formation of amicus curiae networks. Social Networks, v. 36, n. 1, pp. 82-96. Disponível em: https://bit.ly/3mnmRFn. Acesso em: 14 set. 2017. 
BRASIL. Assembleia Nacional Constituinte. 1987a. Anteprojeto Constitucional: Subcomissão VIII-a: subcomissão da Educação, Cultura e Esportes. Brasília, DF: Câmara dos Deputados.

BRASIL. Assembleia Nacional Constituinte. 1987b. Atas de comissões: subcomissão da Educação, Cultura e Esportes. Diário da Assembleia Nacional Constituinte, Brasília, DF.

BRASIL. Assembleia Nacional Constituinte. 1987c. Atas de comissões: subcomissão de Saúde, Seguridade e Meio Ambiente. Diário da Assembleia Nacional Constituinte, Brasília, DF.

BRASIL. Assembleia Nacional Constituinte. 1987d. Atas de comissões: comissão de sistematização. Diário da Assembleia Nacional Constituinte, Brasília, DF. $1 \mathrm{v}$.

BRASIL. Assembleia Nacional Constituinte. 1988a. Atas de plenário N014. Diário da Assembleia Nacional Constituinte, Brasília, DF.

BRASIL. Assembleia Nacional Constituinte. 1988b. Atas de plenário N019. Diário da Assembleia Nacional Constituinte, Brasília, DF.

BURT, Ronald S. Structural holes versus network closures as social capital. In: LIN, Nan.; COOK, Karen; BURT, Ronald S. (ed.). 2001. Social capital: theory and research. New Jersey: Aldine Transaction. pp. 82-96.

CARPENTER, Daniel P.; ESTERLING, Kevin M.; LAZER, David M. J. 1998. The strength of weak ties in lobbying networks: evidence from health-care politics in the United States. Journal of Theoretical Politics, v. 10, n. 4. Disponível em: https://bit.ly/2PZrSrS. Acesso em: 14 set. 2017.

COELHO, Ricardo Corrêa. 1999. Partidos políticos, maiorias parlamentares e tomada de decisão na Constituinte. Tese de Doutorado em Ciência Política. São Paulo: USP. Disponível em: https://bit.ly/3dW8NjJ. Acesso em: 26 abr. 2021.

COMPARATIVE CONSTITUTIONS PROJECT. 2016. Constitution rankings. Disponível em: https://bit.ly/3fIwddD. Acesso em:11 abr. 2016. CONFERÊNCIA NACIONAL DOS BISPOS DO BRASIL. 1986. Por uma nova ordem constitucional. 24를 Assembleia Geral, Itaici, 9 a 18 de abril.

COSTA, Lucas Nascimento Ferraz. 2016. O lobby dos trabalhadores no processo constituinte de 1987-88: um estudo sobre a atuação do DIAP. Revista Estudos Históricos, v. 29, n. 59, pp. 767-786. Disponível em: https://bit.ly/3uCc79p. Acesso em: 15 jan. 2016.

COSTA, Lucas Nascimento Ferraz; TROIANO, Mariele. 2016. Uma análise das atuações do Diap e da Fiesp sob a ótica da teoria institucional. Revista Alabastro, v. 2, n. 8, pp. 56-71. Disponível em: https://bit.ly/3dwEYou. Acesso em: 12 set. 2017. 
ELKINS, Zachary; GINSBURG, Tom; BLOUNT, Justin. 2008. The citizen as founder: public participation in constitutional approval. Temple Law Review, v. 81, n. 2, pp. 361-382.

ESTERLING, Kevin M. 2004. The political economy of expertise: information and efficiency in American national politics. Ann Arbor: University of Michigan Press. Disponível em: https://bit.ly/3sXcMkf. Acesso em: 14 set. 2017.

FERRAJOLI, Luigi. Constitucionalismo principalista e constitucionalismo garantista. In: FERRAJOLI, Luigi; STRECK, Lenio Luiz; TRINDADE, André Karam (org.). 2012. Garantismo, hermenêutica e (neo) constitucionalismo: um debate com Luigi Ferrajoli. Porto Alegre: Livraria do Advogado. pp. 13-58.

GONÇALVES, Cláudia Maria da Costa. 2005. Política dos direitos fundamentais sociais na Constituição Federal de 1988: releitura de uma constituição dirigente. Tese de Doutorado em Políticas Públicas. São Luís: UFMA.

GRANOVETTER, Mark S. 1973. The strength of weak ties. American journal of sociology, v. 78, n. 6, pp. 1360-1380. Disponível em: https://bit.ly/3rSd6R1. Acesso em: 14 set. 2017.

HOJNACKI, Marie; KIMBALL, David C. 1998. Organized interests and the decision of whom to lobby in congress. American Political Science Review, v. 92, n. 4, pp. 775-790. Disponível em: https://bit.ly/2PY2D9c. Acesso em: 14 set. 2017.

KLÜVER, Heike. 2013. Lobbying in the European Union: interest groups, lobbying coalitions and policy change. Oxford: Oxford University Press.

MAHONEY, Christine. 2004. The power of institutions: state and interest group activity in the European Union. European Union Politics, v. 5, n. 4, pp. 441-466. Disponível em: https:/ / bit.ly/39KwNUy. Acesso em: 14 set. 2017.

MANCUSO, Wagner Pralon. 2004. O lobby da indústria no Congresso Nacional: empresariado e política no Brasil contemporâneo. Dados, v. 47, n. 3, pp. 505-547. Disponível em: https://bit.ly/3sN5GzD. Acesso em: 24 ago. 2015.

MAYHEW, David R. 1974. Congress: the electoral connection. Yale: Yale University Press. Disponível em: https://bit.ly/3mlllUe. Acesso em: 14 set. 2017.

MICHILES, Carlos et al. 1989. Cidadão constituinte: a saga das emendas populares. Rio de Janeiro: Paz e Terra.

NORONHA, Eduardo Garuti. 2010. Mudança institucional e a constituinte de 1988: temas e preferências de empresários e 
sindicalistas. Apresentado no $7^{\circ}$ Encontro da ABCP, Recife, 23 a 26 de julho.

OLIVEIRA, Andréa Cristina de Jesus. 2004. Lobby e representação de interesses: lobistas e seu impacto sobre a representação de interesses no Brasil. Tese de Doutorado em Ciências Sociais. Campinas: Unicamp. Disponível em: https://bit.ly/3gF5tvf. Acesso em: 17 fev. 2015.

PIJNENBURG, Bert. 1998. EU lobbying by ad hoc coalitions: an exploratory case study. Journal of European Public Policy, v. 5, n. 2, pp. 303-321.

PILATTI, Adriano. 2008. A Constituinte de 1987-1988: progressistas, conservadores, ordem econômica e regras do jogo. Rio de Janeiro:

Lúmen Júris.

PINHEIRO, Maria Francisca Sales. 1989. O público e o privado na educação na Constituição Brasileira. Humanidades, v. 6, n. 20, pp. 75-85.

SANTOS, Rita Luzia Occhiuze dos. 2004. A participação da mulher no Congresso Nacional Constituinte de 1987 a 1988. Tese de Doutorado em Ciências Sociais. Campinas: Unicamp. Disponível em: https://bit.ly/3u2AtJm. Acesso em: 20 set. 2015.

SARTORI, Giovanni. 1997. Comparative constitutional engineering: an inquiry into structures, incentives, and outcomes. New York: New York University Press. Disponível em: https://bit.ly/3wo7ph7. Acesso em: 11 set. 2017.

TAVARES, Maria das graças Medeiros. 2003. Educação brasileira e negociação política: o processo constituinte de 1987 e a gestão democrática. Maceió: Edufal.

TROIANO, Mariele. 2012. As associações empresariais e o processo

Constituinte de 1987-88. Dissertação de Mestrado em Ciências Humanas. São Carlos: Ufscar.

\section{Anexo 1: fontes para definição das relações dos gráficos de redes}

As relações entre os grupos e constituintes na área da Educação foram defendidas a partir das seguintes fontes: ANDE, ANDES, CPB, SBPC, SINPRO-MG, FITEE e demais membros do Fórum (Brasil, 1987a, pp. 45, 51, 61, 79, 224, 226, 238, 240, 248, 391); FBAPEF (Brasil,1987a, p. 72) CEES (Brasil, 1987b, p. 134); Constituinte Bezerra de Melo (Brasil, 1987b, pp. 53, 120), Constituinte Louremberg Nunes Rocha (Brasil,1987b, pp. 537-538). Constituinte 
Octávio Elísio (Brasil, 1987b, p. 81), Constituinte Hermes Zaneti (Brasil, 1988b, pp. 286-287 e 337-338); CNBB, AEC, AEC e MEC (Brasil, 1987b, P. 183; Conferência Nacional dos Bispos do Brasil, 1986, pp. 15, 239-240).

As relações entre os grupos e constituintes na área da Saúde foram defendidas a partir das seguintes fontes:

Constituinte Geraldo Alckmin (Brasil, 1987c, p. 211), Constituinte Joaquim Sucena (BRASIL, 1987c, pp. 63-64, 66, 70), Constituinte Cunha Bueno (Brasil, 1987c, p. 93), Constituinte Eduardo Jorge (Brasil, 1987c, pp. 51, 61-62, 67, 199); Sindicatão (Brasil, 1987c, p. 112), CONESPE, Aben, CONAM (Brasil, 1987c, pp. 111-113, 123), CEBES (Brasil, 1987c, p. 202), CNRS, FENAM, ABRASCO, MS(Brasil, 1987c, p. 60-61, 133, 141), ABRASCO (Brasil, 1987c, pp. 114115), Fiocruz, CFM, CONASS, Inamps (Brasil, 1987d, 316 pp. 254-255). 


\section{ANÁLISE COMPARADA DAS ESTRATÉGIAS ORGANIZATIVAS DOS LOBBIES NO PROCESSO CONSTITUINTE DE 1987-88}

LUCAS COSTA

Resumo: Neste artigo comparamos as estratégias organizativas dos grupos de interesse nas áreas da Educação, Saúde e Trabalho, durante o processo constituinte de 1987-88. Adaptamos a teoria sobre coalizões lobistas e gráficos de redes sociais para enfatizar os elementos de coesão e estabilidade política dos grupos centrais nas redes. Sustentamos que o lobby se traduziu na divisão entre dois tipos de grupos, definidos pela relação que mantinham em suas áreas de interesse. Essa dinâmica constitui um modelo teórico delineado pela tendência de centralização dos interesses por um único grupo, que representou os demais e, cuja capacidade agregadora, atuou como a principal variável na determinação da força política dos interesses defendidos e, consequentemente, no sucesso do lobby. Os resultados confirmaram a hipótese, mas mostraram que a influência da variável é determinada pela composição das relações entre os grupos, analisadas por meio de gráficos de redes sociais.

Palavras-chave: Lobby; Educação; Saúde; Trabalho; Processos Constituintes; Gráficos de Redes Sociais.

\section{COMPARED ANALYSIS OF THE LOBBIES' ORGANIZATIONAL STRATEGIES IN THE CONSTITUENT PROCESS OF 1987-88}

Abstract: In this article, we compare the different organizational strategies of interest groups in the areas of Education, Health and Work, during the constitutional process of 1987-88. We adapted the theories of lobbying coalition and social network graphs to emphasize the element of political cohesion and stability of the networks' central groups. We argued that the lobby was translated into the division between two types of interest groups, defined by the relationship that 
they maintained in their areas of interest. This dynamic constitutes a theoretical model defined by the tendency of centralization of interests in a single group, which represented all other groups and, which aggregating capacity, played as the main variable in determining the political strength of the interests defended and, consequently, in the success of the lobby. The results confirmed the hypothesis, but showed that the influence of this variable is determined by the composition of the relations between the groups, analyzed by social network graphs.

Keywords: Lobby; Education; Health Care; Labor; Constitutional Drafting; Social Network Analysis.

Recebido: 20/06/2018Ａprovado: 30/03/2021 